\title{
Eag and HERG potassium channels as novel therapeutic targets in cancer
}

\author{
Viren Asher ${ }^{1 *}$, Heidi Sowter ${ }^{2}$, Robert Shaw ${ }^{3}$, Anish Bali ${ }^{4}$, Raheela Khan ${ }^{5}$
}

\begin{abstract}
Voltage gated potassium channels have been extensively studied in relation to cancer. In this review, we will focus on the role of two potassium channels, Ether à-go-go (Eag), Human ether à-go-go related gene (HERG), in cancer and their potential therapeutic utility in the treatment of cancer. Eag and HERG are expressed in cancers of various organs and have been implicated in cell cycle progression and proliferation of cancer cells. Inhibition of these channels has been shown to reduce proliferation both in vitro and vivo studies identifying potassium channel modulators as putative inhibitors of tumour progression. Eag channels in view of their restricted expression in normal tissue may emerge as novel tumour biomarkers.
\end{abstract}

\section{Introduction}

Cancer is one of the major killers throughout the world. It is estimated that a total of $1,529,560$ new cancer cases and 569,490 deaths from cancer will occur in the United States in 2010 [1]. There is increasing evidence that ion channels are involved in various processes characteristic of cancer cells such as uncontrolled cell proliferation, migration and survival in hypoxic conditions [2].

Ion channels are integral membrane proteins that mediate the transfer of ions through the hydrophobic lipid bilayer of the cell membrane. They play an important role in a variety of functions that range from nerve/ muscle excitation [3], regulation of blood pressure [4], through to sperm motility and capacitation [5]. Potassium $\mathrm{K}^{+}$channels comprise the largest family of ion channels encoded by $\sim 300$ genes with phenotypic diversity generated through alternative splicing, variable association of (homo/heteromultimerisation) of channel subunits and posttranslational modifications. In normal cellular function, $\mathrm{K}^{+}$channels are the main determinants of a cell's resting membrane potential. $\mathrm{K}^{+}$channels have also been linked to cell volume control [6,7], cell cycle progression[8] and cardiac repolarisation[9].

In recent years, expression of several $\mathrm{K}^{+}$channel subtypes has been described in a plethora of malignancies.

\footnotetext{
* Correspondence: viren.asher@nottingham.ac.uk

${ }^{1}$ Research fellow, Department of Obstetrics and Gynaecology, School of Graduate Medicine and Health, Royal Derby Hospital, Uttoxeter road, Derby DE22 3DT, UK

Full list of author information is available at the end of the article
}

In particular the role of voltage gated $\mathrm{K}^{+}$channels in cancer, has been reviewed in several excellent publications $[2,10,11]$. This review will focus specifically on the Eag and HERG voltage gated $\mathrm{K}^{+}$channels with their potential therapeutic applications in cancer.

\section{Historical perspective}

The Eag gene, present on locus 50 of the X chromosome of the fruitfly Drosophila melanogaster, is a mutant of the Shaker gene [12], so called since flies afflicted with this mutation exhibited slow, rhythmic shaking of the legs with minimal shaking of wings or abdomen on exposure to ether anaesthesia $[13,14]$. In a bid to find homologous Eag genes in Drosophila and mammals, a further two-Elk (Eag like gene) and Erg (Eag related gene) were discovered. All members of the Eag family have $>85 \%$ DNA sequence homology [15]. The International Union of Basic and Clinical Pharmacology (IUPHAR) have classified the Eag family as shown in Table 1. [16]

The Eag channel has also been cloned from rat (rEag) [17], and bovine retina [18]. The first human Eag (hEag), located on chromosome 1q 32-41, was cloned from cultured myoblasts at the onset of fusion, but was absent in adult skeletal muscle, $[19,20]$ indicating that expression of hEag is linked to the early stages of syncytial myotube formation.

The human HERG gene was the first member of the Ether-a go-go family to be isolated by screening of human hippocampal cDNA with the mouse homologue 
Table 1 Members of the Eag family

\begin{tabular}{lll}
\hline Previous name & Official IUPHAR name & Human gene name \\
\hline $\begin{array}{l}\text { Eag1, KCNH1a, } \\
\text { Eag1a, Eag1b }\end{array}$ & $\mathrm{Kv} 10.1$ & $\mathrm{KCNH} \mathrm{1}$ \\
\hline Eag2, KCNH5 & $\mathrm{Kv} 10.2$ & $\mathrm{KCNH} 5$ \\
\hline HERG, erg1, hergb & $\mathrm{Kv} 11.1$ & $\mathrm{KCNH} 2$ \\
\hline erg2 & $\mathrm{Kv} 11.2$ & $\mathrm{KCNH} \mathrm{6}$ \\
\hline erg3 & $\mathrm{Kv} 11.3$ & $\mathrm{KCNH} 7$ \\
\hline elk3, elk1 & $\mathrm{Kv} 12.1$ & $\mathrm{KCNH} 8$ \\
\hline elk2, BEC 1 & $\mathrm{Kv} 12.2$ & $\mathrm{KCNH} 3$ \\
\hline elk1, BEC 2 & $\mathrm{Kv} 12.3$ & $\mathrm{KCNH} 4$ \\
\hline
\end{tabular}

Eag- ether à-go-go, HERG- Human ether à-go-go related gene, erg- ether àgo-go related gene, elk- ether à-go-go like, BEC- Brain Eag-like channel, KCNHpotassium channel $\mathrm{H}$ family.

of Eag and was localised to chromosome 7 [15]. It has also been implicated in Long QT Syndrome 2 [21].

\section{Location and function of Eag and HERG}

Eag channels are expressed in fusing myoblasts and been posulated to have a role in their hyperpolarisation that preceeds their fusion [19]. Eag channels are also selectively expressed in the brain and placenta of rat and humans $[19,22]$, with diffuse immunohistochemical reactivity in rat brain. They are very noticeable in the perinuclear space of cells and proximal regions of the extensions, both in rat and human brain. The real time PCR analysis of rat brain revealed higher Eag 1 expression in olfactory bulb, cerebral cortex, striatum, hippocampus, hypothalamus, and cerebellum, and low expression in thalamus and brainstem [23].

The function of Eag channels in neurotransmitter release at the neuromuscular junctions to initiate action potential in Drosophila melanogaster larvae is well known [24] and recently genes for shal and shaker channels in the central nervous system of Drosophila melanogaster have been shown to be reciprocally regulated resulting in a target dependent, homeostatic modulation of synaptic transmission [25]. Eag channels are also involved in odour transduction [26] and are encoded in seizure locus in Drosophila [27]. In mammals, although Eag channels have been shown to be present in rat brain, their exact physiological function is not known, but in rat retina, they are known to be involved in the dark current-loop of photoreceptors. [28].

In contrast to Eag channels, HERG channels are more widely expressed and their functions differ according to their localization (Table 2). The HERG channel has a dominant presence in normal human myocardium where it is involved in the repolarisation phase of the cardiac action potential [21]. Mutations of this channel causes long QT syndrome 2 leading to cardiac arrhythmias and sudden death [29]. Gain of function mutations in this channel lead to short QT syndrome and sudden infant death [30].

\section{Structure of Eag channel family}

Members of the Eag family share the same structure of other voltage-gated potassium channels, comprising of four identical $\alpha$ subunits each consisting of six membrane spanning domains (S1-S6) with cytoplasmic amino $(\mathrm{N})$ and carboxy $(\mathrm{C})$ termini. The ion-conduction pathway or pore region $(\mathrm{P})$ is positioned between S5-S6, with voltage being sensed predominantly by the chain of positive arginine or lysine residues based at every third position, separated by two hydrophobic residues within the S4 domain which acts as a voltage sensor [31,32]. All the domains are well conserved among all the family members of Eag namely Eag, HERG and Elk, including the positively charged amino acids in the S4 segment [15]. The N terminal consists of a Per-Arnt-Sim (PAS) domain [33], a hypoxia sensor leading to the activation of hypoxia inducible factor (HIF1), resulting in increased glycolysis and angiogenesis thus conferring a selective growth advantage to cancer cells in a hypoxic environment $[34,35]$. The $\mathrm{C}$ terminus consists of a cyclic nucleotide binding domain (cNBD) and tetramerization-coil-coil domain with an Endoplasmic reticulum retention signal (RXR), which is involved in the tetramerization and functional expression of the channels [36,37]. Also present on the $\mathrm{C}$ terminus are multiple signalling modules including putative nuclear export sequences (NES) and nuclear localization sequences (NLS) with binding sites for calmodulin (CaM), calcium/CaM-dependent protein kinaseII (CaMKII) [38]. These NES and NLS play an important role in perinuclear localization of these channels. The structure of Eag channels is well conserved in Drosophila, mouse, rat and humans. The sequence comparisons among family members has shown that two members of the same subfamily in different species share about $60-70 \%$ amino acid identities from S1 through to the cNBD segment [39].

\section{Eag and HERG channels in cancer}

The initial study reporting on a potential link between the Eag family of channels and cancer showed that high levels of herg mRNA were present in 17 cancer cell lines of different species (human and murine) with distinct histogenesis. These included neuroblastoma, rhabdomyosarcoma, adenocarcinoma, lung microcytoma, pituitary tumours, insulinoma $\mathrm{B}$ cells and monoblastic leukaemia [40].

Following this discovery, Walter Stuhmer's group showed that Chinese Hamster ovary ( $\mathrm{CHO}$ ) cells when transfected with rEag exhibited a transformed cancerous phenotype characterised by the ability of the cells to grow in a low concentration (0.5\%) of serum, displaying increased DNA synthesis, higher metabolic activity and 
Table 2 Location and function of HERG channel

\begin{tabular}{|c|c|c|}
\hline Organ & Function & References \\
\hline Heart & Repolarisation of cardiac action potential & {$[21,29,30]$} \\
\hline CNS & Maintain membrane potential and development of neurons of spinal cord and carotid glomus cells & {$[92,93]$} \\
\hline GIT & Regulate motility of gut & [94] \\
\hline Endocrine system & Secretion of insulin and modulating epinephrine release in chromaffin cells & {$[95,96]$} \\
\hline
\end{tabular}

loss of contact inhibition [22]. The same group also demonstrated that herg mRNA is also expressed in MCF-7 (breast cancer), SHSY-5Y (neuroblastoma) and He-La (carcinoma cervix) cell lines. Inhibition by antisense oligonucleotides decreased the RNA content and functional protein of EF119 (breast cancer) cells [22]. Furthermore subcutaneous implantation of $\mathrm{CHO}$ cells expressing Eag channels in severe combined immune deficiency (SCID) mice lead to aggressive tumours showing intratumoral necrosis [22]. Eag channels also appear to impart a selective advantage for tumour cells in hypoxia by production of hypoxia inducible factor-1 (HIF-1) and thereby increasing vascular endothelial growth factor (VEGF) and increased vascularisation [35]. Additionally expression of Eag channels has been shown to be associated with re-organisation of the cytoskeleton and extracellular matrix thereby influencing adhesion, proliferation and metastasis of tumour cells [41]. These experiments collectively demonstrate the oncogenic potential of Eag channels and hence their activation in cancer cells.

Eag channels have also been shown to have increased expression in various cancer cell lines namely IGR1, IPC298, and IGR39 (melanoma) [42], SH-SY5Y (neuroblastoma) [43] and MCF-7 (breast cancer) cell lines and various cancers such as gliomas [44], cervical cancers [45], colon carcinoma [46], gastric cancers [47] and sarcomas [48].

HERG channels have been shown to be expressed in various cell lines like human and murine neuroblastoma, human leukaemia (preosteoclastic, lymphoblastic, myelogenous and promyelocytic) [49-51], human rhabdomyosarcoma, colon carcinoma, mammary carcinoma, squamous cervical, endometrial cancer, gastric and glioblastoma [52-55].

The first tissue expression of HERG channels in cancer showed that herg mRNA and HERG protein was expressed in 67 and $82 \%$ of endometrial cancer tissues compared to $18 \%$ of normal endometrium with no expression seen in endometrial hyperplasia [56]. The same group also showed that both herg gene and HERG protein were expressed in blast cells of acute myeloid leukaemia patients while no expression was seen in peripheral blood mononuclear cells [57]. Similar results were demonstrated in lymphocytic leukaemia with no HERG expression in normal lymphocytes [51]. Prolactinoma cells have been shown to express the herg transcript and HERG channels have been suggested to a play a role in prolactin secretion [58].

Further investigation of HERG channels in cancer invasion and metastasis revealed that, in addition to the high expression of herg gene and HERG protein in colorectal cancers, highest expression is seen in metastatic cancers with absence in normal colon and adenomas. HERG channels also modulate the invasiveness of colon cancer thought to be directly related to the amount of HERG protein present on the cell membrane [59] and confirmed by HERG expression in gastric [60] and melanoma cells [61]. Increasing expression is associated with high grade tumours, furthermore knocking down of herg gene by siRNA resulted in reduced proliferation and invasiveness of the cells. In contrast high grade gliomas have shown lower expression of herg gene compared to high grade tumours [44] while there is loss of HERG expression in renal cell cancer compared to normal kidney [62].

These studies show that Eag and HERG channels are expressed by a variety of cancer cell lines and tissues with Eag channel showing an oncogenic potential while HERG channels are associated with more aggressive tumours and have a role in mediating invasion.

\section{Eag in cancer prognosis}

Eag has been shown to have high expression in colorectal cancers compared to adenomas and its expression correlates with tumour size, lymph node metastasis and Dukes staging suggesting its role as a prognostic marker [63]. Similar studies in gastric cancer have shown that higher Eag expression is associated with higher stage and lymph node metastasis, which are known poor prognostic markers [47]. Recently Eag has been shown to be present in acute myeloid leukaemia and the channel expression strongly correlated with increasing age, higher relapse rates and significantly shorter survival [64].

\section{Regulation of Eag channels in cancer}

Eag channels have been found to be up regulated in mouse colon on treatment with chemical carcinogens such as Dimethylhydrazine (DMH) and $N$-methyl- $N$-nitrosourea (MNU) compared to chemically induced Dextran sulphate sodium (DSS) colitis. These carcinogens are well 
known to induce premalignant changes in the colon mucosa. Moreover there was higher Eag protein expression and mRNA in the distal mouse colon treated by $\mathrm{DMH}$ and MNU compared to the untreated proximal colon which suggests their role in pathogenesis of colon cancer [46]. Estrogen has also been shown to increase Eag expression by its action on Estrogen receptor $\alpha(E R \alpha)$ in cervical and lung carcinoma cells [65]. The same group also showed that keratinocytes expressing HPV oncogene expressed Eag compared to its lack of expression in normal keratinocytes. Higher Eag expression was also demonstrated in cervical cancer cells containing high risk HPV16 and 18 [65]. Other factors that increased Eag expression and activity are Insulin like growth factor-1 (IGF1) in Breast (MCF-7) cells through the akt pathway [66] and Arachidonic acid (AA)in melanoma cells [67].

\section{Use of Eag expression as a potential tumour marker}

The potential of using Eag channel expression as a tumour marker is supported by observation that Eag channels show higher expression in all patients with cervical cancer [45]. In the normal group, there was higher expression in patients with human papilloma virus (HPV) infection who had negative smears and other premalignant conditions such as atypical hyperplasia of endometrium and serous cystadenoma of ovary. Moreover one patient with a negative smear had an unexpected finding of endocervical adenocarcinoma with positive Eag expression at hysterectomy suggesting its role as tumour marker and a potential early predictor of cancer [45].

Injection of poly-lysine containing recombinant anti Eag1 antibody conjugated to Cy5.5 into immune deficient mice grafted with MBA-MB-435 S mammary cancer cell line clearly showed the tumour and the sentinel lymph node on near infrared fluorescent imaging (NIF) in 24 hours. [68].

The increased expression of Eag channel in the mouse colon as a result of DMH exposure has been shown to be associated with poor survival. Eag has also be shown to be present at premalignant stage in the development of colon cancer therefore Eag transcripts present in stool samples and rectal biopsies may be useful as diagnostic and prognostic markers [46]. Thus Eag could be potentially used as a tumour marker for various cancers.

The next question now arises: what is the role of these channels in proliferation and cell cycle and how are they associated with carcinogenesis? We have now started to get some answers but still are quite far away from determining their exact role in carcinogenesis

\section{Role of Eag and HERG channels in cell proliferation and the cell cycle}

The indication of an erg like inward rectifier being involved in cell cycle came initially from neuroblastoma cells that showed current characteristics resembling those of erg channels with a rapid reduction in the current when the cells were synchronised in G0/G1 phase or G1/S boundary of the cell cycle [49]. This novel inward rectifier also maintained the resting membrane potential at a more negative value an important feature of cancer cells[49]. Subsequently a slow activating potassium channel current similar to rat Eag (rEag) in neuroblastoma cells (h-Eag) was characterised and it was demonstrated that the electrical current was reduced to $5 \%$ of the control value when the neuroblastoma cells were synchronised to G1 phase of the cell cycle on treatment of retinoic acid, thus indicating their role in cell cycle [43].

Xenopus oocytes are a useful model for the study of the cell cycle as they are indefinitely arrested in the G2 phase of the first meiotic cycle, until a hormonal stimulus, for example progesterone, induces progression of meiotic division. Rat Eag (rEag) channels expressed in Xenopus oocytes reduce their activity when their maturation is induced by progesterone and also by Mitosis promoting factor as the oocytes progress through the cell cycle, denoting that Eag channels are cell cycle sensitive [69]. The partial syncronization of Xenopus oocytes cells in G0/G1 or M phase greatly increased the block by intracellular sodium $\left(\mathrm{Na}^{+}\right)$and caesium [70] which may be due to interaction of Eag channels with microtubules which are depolymerised during cell cycle [71]. Human Eag (hEag) has been showed to be transiently expressed before myoblast fusion and contribute to the hyperpolarisation that drives the process. As myoblast fusion involves withdrawal from cell cycle to form skeletal muscle, Eag channels have been suggested to be involved in their cell cycle regulation [19].

The expression of herg gene is not detectable in peripheral blood mononuclear cells (PBMNC) and circulating $\mathrm{CD}_{34}{ }^{+}$cells, but then is rapidly expressed as soon as they enter $\mathrm{S}$ phase on upon treatment with cytokine/ growth factor mixture, suggesting that HERG channels play a role in cell cycle regulation [57]. Subsequently an $\mathrm{N}$-truncated herg1b isoform was shown to coexist with herg1 RNA in human myeloid leukaemias. Both HERG1 and HERG1b proteins were demonstrated on the plasma membranes and can form heterotetramers. The expression of these isoforms was found to oscillate during cell cycle, with HERG1 protein upregulated in G1 phase and down regulated in $\mathrm{S}$ phase, while the $\mathrm{N}$ truncated HERG1b isoform upregulated in $\mathrm{S}$ phase [52] accounting for the variations in HERG currents in the mitotic cycle as shown in neuroblastoma cells [49].

The Eag and HERG channels have been shown to be inhibited in tissues of varying histology by Eag and HERG blockers which are reviewed in $[10,11,72]$. Imipramine a known Eag blocker induces apoptosis in 


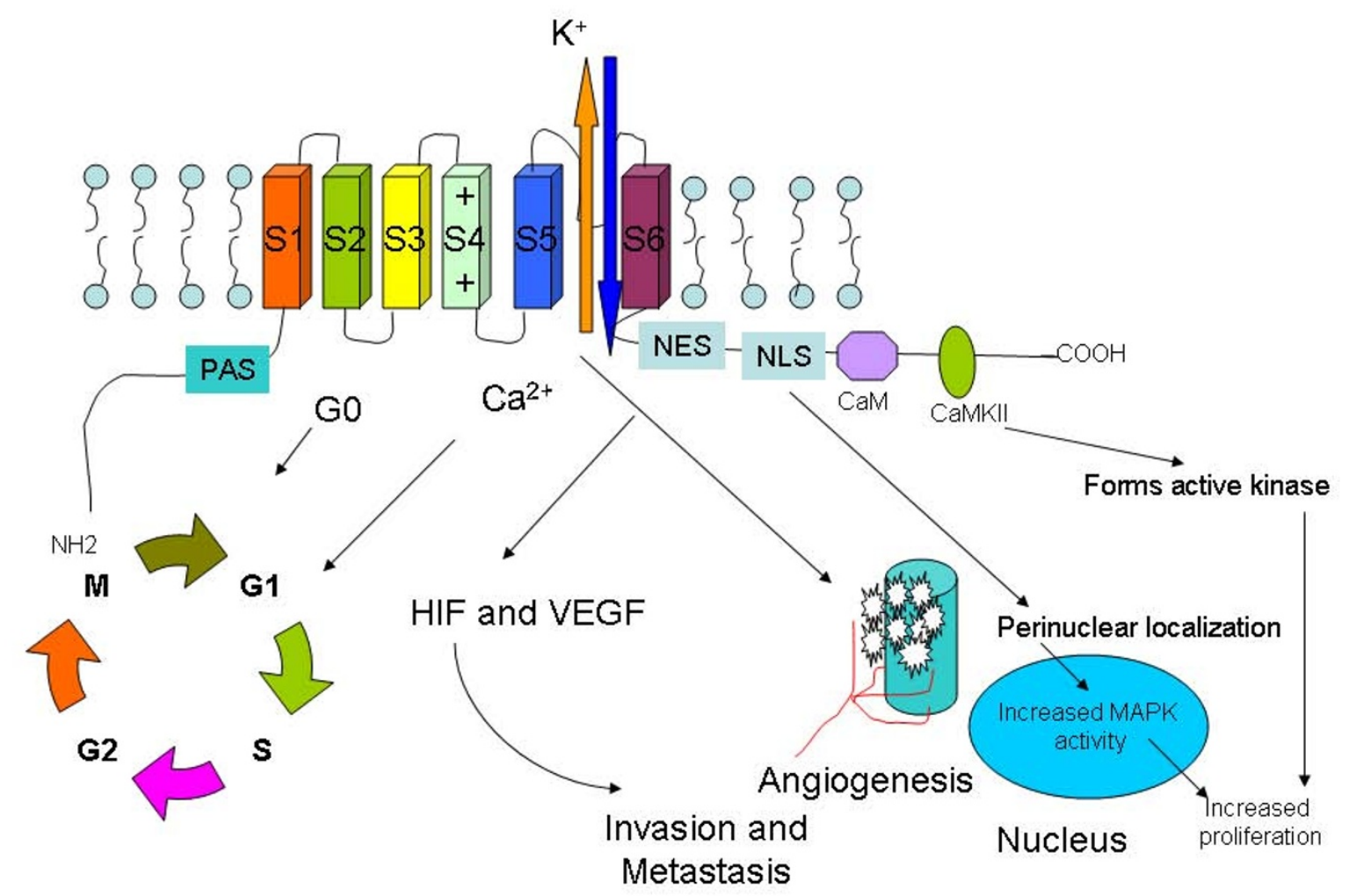

Figure 1 Potential mechanisms of malignant transformation by $\mathrm{K}^{+}$channels. Increased expression of $\mathrm{K}^{+}$channels on cell membrane results in increased influx of $\mathrm{Ca}^{2+}$ ions resulting in increased transition of cells through G1/S phase of cell cycle. The channels in presence of hypoxia lead to release of HIF1 and VGEF factor leading to increased angiogenesis and subsequent invasion and metastasis of tumours. The nuclear localisation sequence (NLS) in the C terminus on activation results in perinuclear localisation of the channel leading to activation of Mitogen activated protein kinase (MARP) pathway resulting in increased cell proliferation. The Eag channels also act through the Ca calmodulin pathway to activate cell proliferation.

acute myeloid leukaemia cells via the caspase-3 activation [73] while it has been shown that HERG expressing cells are more sensitive to apoptosis induced by hydrogen peroxide, with reversal of effect on blocking with a HERG blocker dofetilide [74]. The same authors also showed co-expression of HERG and TNF $\alpha$ on cell membrane of tumour cells, leading to increased activity of the transcription factor nuclear factor kappa B facilitating tumour cell proliferation [74]. Thus both Eag and HERG channels are associated with cell proliferation and play an important role in modulation of cell cycle.

\section{Hypothetical model of potential oncogenic mechanisms} (Summarised in Figure 1)

As we have discussed, there is considerable evidence to support a role for Eag and HERG channels in cancer.
However it is not at all clear whether these channels play causal roles in oncogenesis or whether the oncogenic process results in aberrant expression and activation of the Eag channel family. Identifying the mechanism underlying malignant transformation involving Eag channels especially is further compounded by a lack of specific pharmacological agents. Despite these, several theories have been advanced as to how Eag and HERG channels could promote malignant transformation as discussed below:

It is well known that $\mathrm{K}^{+}$channels play an important role in regulation of membrane potential in both excitable and non excitable cells. Nilius et al.[75], proposed that in human melanoma cells overexpression of $\mathrm{K}+$ channels leads to hyperpolarisation as a result of the efflux of cations from the cell interior, which subsequently causes 
inward movement of $\mathrm{Ca}^{2+}$ ions to maintain the membrane potential. The role of $\mathrm{Ca}^{2+}$ in the transition from the $\mathrm{G} 1$ to the $\mathrm{S}$ phase during mitosis in mammalian cells is welldocumented and $\mathrm{Ca}^{2+}$ acts as a pacemaker that initiates the timing of cell cycle transitions [76]. Therefore increased intracellular $\mathrm{Ca}^{2+}$ can trigger the rapid transition of cells through the G1 to $\mathrm{S}$ phase leading to enhanced proliferation. However the pathway through which this $\mathrm{Ca}^{2+}$ entry occurs is not known and change in resting potential is not always observed when the cells are inhibited by potassium channel blockers [77].

An alternative mechanism postulated concerns the inverse relationship between cell volume and $\mathrm{K}^{+}$channels. Increasing $\mathrm{K}^{+}$channel activity leads to cell shrinkage which then deforms the cell and modifies the cytoskeletal components through changes in protein kinases or phosphatases that control cell proliferation [78]. This hypothesis is supported by the fact that $\mathrm{K}^{+}$ channel blockers lead to an increase in cell volume and inhibit proliferation. However, it is argued that astrocytes that are involved in the formation of the blood brain barrier [79], despite having high expression of $\mathrm{K}^{+}$ channels undergo a reduction in cell volume in presence of $\mathrm{K}^{+}$channel blockers while L-glutamate initiated $\mathrm{K}^{+}$ influx into the cell leads to their swelling [80]

Hypoxia has been implicated as a stimulus for rapidly growing tumours where, hypoxic areas lead to altered cellular mechanisms consequently causing either an increase in oxygen or activation of other mechanisms not requiring oxygen. The induction of hypoxia inducible factor (HIF-1 $\alpha$ ) by hypoxia, subsequently leads to the transcriptional activation of genes encoding erythropoietin, VEGF and glycolytic enzymes, all thought to be involved in various aspects of tumour initiation, growth and metastasis [81]. HEK cells transfected with Eag channels lead to increased production of HIF- $\alpha$ in under hypoxic conditions and as Eag channels are overexpressed in various cancers, they could potentially confer selective advantage to cancer cells in hypoxic conditions [35].

There has been increasing evidence linking mutant Eag channels that contain non conducting subunits lacking functional pore with cell proliferation. Hegle et al [82] demonstrated the voltage dependent gating of the Eag channel controlled the cell proliferation and Mitogen activated protein kinase (MAPK) signalling pathway by a mechanism that is independent of $\mathrm{K}^{+}$influx through the channel. Eag channels also act as a scaffold for and activate Calcium -Calmodulin activated kinase II (CaMKII), forming a complex which remains active even in the presence of low calcium [83], leading to dysregulation of cell proliferation and apoptosis resulting in genesis of cancer [84].

Activated Nuclear localization sequence (NLS) located on the $\mathrm{C}$ terminus of Eag channels results in activation of Mitogen activated protein kinase (MAPK) signal transduction pathway that regulates cell morphology [38]. Sarcoma and cervical cells $[48,65]$ have been shown to have increased perinuclear localization of Eag channels and NLS may play an important role in its oncogenic mechanism.

\section{Therapeutic application}

From the above studies it is clear that blocking Eag and HERG channels inhibits cell proliferation and therefore disease progression. These channels have been demonstrated in the cell membrane by functional studies and therefore are accessible targets for modulation by drugs. Moreover Eag channels have restricted expression in the central nervous system, placenta and in myoblasts just prior to fusion but are expressed in cancer cell lines of various origin and cancer tissues making them a potential marker and target for various drugs $[10,19,22,85,86]$.

Both Eag and HERG belong to the same family of voltage gated $\mathrm{K}^{+}$channels and share $47 \%$ of the amino acid sequence [15]. Thus any drug acting on Eag channel may also block HERG channels leading to prolonged QT syndrome, cardiac arrhythmias and sudden death $[21,29]$. Therefore there is a need for specific targeted blockers for maximal inhibitory effect and reduction in side effects.

\section{Several approaches have been used to target or inhibit Eag channels in cancer}

1. Chemical blockers: Imipramine and astemizole have been shown to abolish Eag currents and inhibit the cell proliferation of tumour cells and are easily available in the market for use $[87,88]$. However both these drugs have undesirable cardiovascular side effects due to HERG blockade which limits their applicability in treating cancer.

2. Monoclonal antibodies: These act as highly specific molecules for a targeted blockade of the channels and minimise the side effects associated with action on homologous channels. These antibodies may also be potentially used as vehicles for therapeutic agents for a site specific action [86]. A monoclonal antibody has been designed against Eag1 with no effect on Eag2 and HERG channels. This antibody has been shown to reduce the $\mathrm{K}^{+}$channel currents in isolated cells and also inhibit the growth of cancer cells from various organs both in vitro and vivo. Hence evidence in favour of this antibody may potentially be used either alone or in association with current established treatment to reduce the dose and associated side effects of conventional chemotherapeutic drugs [89].

3. Inhibition of cell growth using small interfering RNA (si RNA) technologies: This is a potential new 
approach to knock down gene expression and reduce the amount of protein that is produced. The activity of Eag has been shown to be silenced by the use of Eag specific siRNA which result in reduced protein expression and inhibition of cell proliferation in various cancer cell lines with minimal non-specific side effects [90]. The challenge with this approach is the design of an appropriate transport vehicle and delivery of siRNA to the target organ and currently the subject of intense research.

\section{Targeting HERG channels}

1. Short hairpin (sh) RNA technology: The knock down of herg gene expression by the use of shRNAs for HERG1 and the HERG-1b isoform, reduced growth rate, cell viability and inhibited colony formation of neuroblastoma cells restricting them to G0/G1 phase of cell cycle. There was also inhibition of tumour cells injected into nude mice on treatment with sh RNA. Thus this technology can be potentially used in silencing of herg gene and subsequently the reduction in growth of tumour, but its effect on the heart needs to be evaluated and the delivery of these molecules to target organs still poses a significant challenge [91].

2. Use of HERG blockers including E-4031 and ergtoxin have still not been tested in vivo studies but do show a promising role in potential use with chemotherapeutic agents or in chemoresistant disease. However tight cardiac monitoring will be needed due to the development of drug induced Long QT syndrome.

\section{Conclusion}

Both Eag and HERG channels have been shown to be present in cancers of differing origin and have a role in cell proliferation, progression and survival. There is abundant data on the effects of various blockers on the inhibition of cell growth and these channels may prove to be promising novel therapeutic targets for the treatment for cancer. They can be potentially be used in conjunction with chemotherapeutic agents or can be used in chemoresistant disease to improve survival. Eag due to its restricted expression shows a promising role as a potential tumour marker.

\footnotetext{
Author details

${ }^{1}$ Research fellow, Department of Obstetrics and Gynaecology, School of Graduate Medicine and Health, Royal Derby Hospital, Uttoxeter road, Derby DE22 3DT, UK. ' Lecturer, Biological and Forensics Sciences, University of Derby, Keldeston road, Derby DE22 1GB. UK. ${ }^{3}$ Professor and Head, Department of Obstetrics and Gynaecology, School of Graduate Medicine and Health, Royal Derby Hospital, Uttoxeter road, Derby DE22 3DT. UK.
}

${ }^{4}$ Consultant Gynaecological Oncologist, Department of Obstetrics and Gynaecology, Royal Derby Hospital, Uttoxeter road, Derby DE22 3NE. ${ }^{5}$ Associate Professor, Department of Obstetrics and Gynaecology, School of Graduate Medicine and Health, Royal Derby Hospital, Uttoxeter road, Derby DE22 3DT. UK

\section{Authors' contributions}

VA wrote the manuscript, RK and HS conceptualised the project and helped in preparation of manuscript, $\mathrm{RS}$ and $\mathrm{AB}$ corrected the manuscript.

\section{Competing interests}

The authors declare that they have no competing interests.

Received: 30 September 2010 Accepted: 29 December 2010 Published: 29 December 2010

\section{References}

1. Jemal A, et al: Cancer statistics, 2010. CA Cancer J Clin 2010, 60(5):277-300.

2. Fiske $\mathrm{J}$, et al: Voltage-sensitive ion channels and cancer. Cancer Metastasis Rev 2006, 25(3):493-500.

3. Swartz KJ: Sensing voltage across lipid membranes. Nature 2008, 456(7224):891-7.

4. Brayden JE, Nelson MT: Regulation of arterial tone by activation of calcium-dependent potassium channels. Science 1992, 256(5056):532-5.

5. Darszon A, et al: lon channels in sperm motility and capacitation. Soc Reprod Fertil Suppl 2007, 65:229-44.

6. Lang F: Mechanisms and significance of cell volume regulation. J Am Coll Nutr 2007, 26(5 Suppl):613S-623S.

7. Sontheimer $\mathrm{H}$ : An unexpected role for ion channels in brain tumor metastasis. Exp Biol Med (Maywood) 2008, 233(7):779-91.

8. Blackiston DJ, McLaughlin KA, Levin M: Bioelectric controls of cell proliferation: ion channels, membrane voltage and the cell cycle. Cell Cycle 2009, 8(21):3519-28.

9. Perrin MJ, et al: Human ether-a-go-go related gene (hERG) $\mathrm{K}+$ channels: function and dysfunction. Prog Biophys Mol Biol 2008, 98(2-3):137-48.

10. Pardo $L A$, et al: Role of voltage-gated potassium channels in cancer. $J$ Membr Biol 2005, 205(3):115-24.

11. Conti M: Targeting K+ channels for cancer therapy. J Exp Ther Oncol 2004, 4(2):161-6.

12. Catsch A: Eine erbliche storung des Bewegungsmechanismus be Drosophila Melanogaster. Z Ind Abst Vererb 1944, 82:62-66.

13. Kaplan WD, Trout WE: The behavior of four neurological mutants of Drosophila. Genetics 1969, 61(2):399-409.

14. Ganetzky B, Wu CF: Drosophila mutants with opposing effects on nerve excitability: genetic and spatial interactions in repetitive firing. $J$ Neurophysiol 1982, 47(3):501-14.

15. Warmke JW, Ganetzky B: A family of potassium channel genes related to eag in Drosophila and mammals. Proc Natl Acad Sci USA 1994, 91(8):3438-42.

16. Harmar AJ, et al: IUPHAR-DB: the IUPHAR database of $G$ protein-coupled receptors and ion channels. Nucleic Acids Res 2009, 37 Database: D680-5.

17. Ludwig J, et al: Functional expression of a rat homologue of the voltage gated ether a go-go potassium channel reveals differences in selectivity and activation kinetics between the Drosophila channel and its mammalian counterpart. EMBO J 1994, 13(19):4451-8.

18. Frings $S$, et al: Characterization of ether-a-go-go channels present in photoreceptors reveals similarity to IKx, a $\mathrm{K}+$ current in rod inner segments. J Gen Physiol 1998, 111(4):583-99.

19. Occhiodoro T, et al: Cloning of a human ether-a-go-go potassium channel expressed in myoblasts at the onset of fusion. FEBS Lett 1998, 434(1-2):177-82.

20. Bijlenga $\mathrm{P}$, et al: T-type alpha $1 \mathrm{H} \mathrm{Ca} 2+$ channels are involved in $\mathrm{Ca} 2+$ signaling during terminal differentiation (fusion) of human myoblasts. Proc Natl Acad Sci USA 2000, 97(13):7627-32

21. Curran ME, et al: A molecular basis for cardiac arrhythmia: HERG mutations cause long QT syndrome. Cell 1995, 80(5):795-803.

22. Pardo LA, et al: Oncogenic potential of Eag K channels. EMBO J 1999, 18(20):5540-7.

23. Martin S, et al: Eag1 potassium channel immunohistochemistry in the CNS of adult rat and selected regions of human brain. Neuroscience 2008, 155(3):833-44. 
24. Wu CF, et al: Potassium currents in Drosophila: different components affected by mutations of two genes. Science 1983, 220(4601):1076-8.

25. Bergquist S, Dickman DK, Davis GW: A hierarchy of cell intrinsic and target-derived homeostatic signaling. Neuron 2010, 66(2):220-34.

26. Dubin $A E$, Liles MM, Harris GL: The $K+$ channel gene ether a go-go is required for the transduction of a subset of odorants in adult Drosophila melanogaster. J Neurosci 1998, 18(15):5603-13.

27. Titus SA, Warmke JW, Ganetzky B: The Drosophila erg K+ channel polypeptide is encoded by the seizure locus. J Neurosci 1997, 17(3):875-81.

28. Bauer CK, Schwarz JR: Physiology of EAG K+ channels. J Membr Biol 2001 182(1):1-15

29. Sanguinetti $M C$, et al: A mechanistic link between an inherited and an acquired cardiac arrhythmia: HERG encodes the IKr potassium channel. Cell 1995, 81(2):299-307.

30. Brugada $\mathrm{R}$, et al: Sudden death associated with short-QT syndrome linked to mutations in HERG. Circulation 2004, 109(1):30-5.

31. Warmke J, Drysdale R, Ganetzky B: A distinct potassium channel polypeptide encoded by the Drosophila eag locus. Science 1991, 252(5012):1560-2

32. Yellen $\mathrm{G}$ : The voltage-gated potassium channels and their relatives. Nature 2002, 419(6902):35-42

33. Morais Cabral $\mathrm{JH}$, et al: Crystal structure and functional analysis of the HERG potassium channel $\mathrm{N}$ terminus: a eukaryotic PAS domain. Cell 1998, 95(5):649-55.

34. Semenza GL: Hypoxia-inducible factor 1 and the molecular physiology of oxygen homeostasis. J Lab Clin Med 1998, 131(3):207-14

35. Downie BR, et al: Eag1 expression interferes with hypoxia homeostasis and induces angiogenesis in tumors. J Biol Chem 2008, 283(52):36234-40.

36. Ludwig J, Owen D, Pongs O: Carboxy-terminal domain mediates assembly of the voltage-gated rat ether-a-go-go potassium channel. EMBO J 1997, 16(21):6337-45.

37. Jenke $M$, et al: C-terminal domains implicated in the functional surface expression of potassium channels. EMBO J 2003, 22(3):395-403.

38. Sun XX, Bostrom SL, Griffith LC: Alternative splicing of the eag potassium channel gene in Drosophila generates a novel signal transduction scaffolding protein. Mol Cell Neurosci 2009, 40(3):338-43.

39. Ganetzky B, et al: The eag family of $\mathrm{K}+$ channels in Drosophila and mammals. Ann N Y Acad Sci 1999, 868:356-69.

40. Bianchi $L$, et al: herg encodes a K+ current highly conserved in tumors of different histogenesis: a selective advantage for cancer cells? Cancer Res 1998, 58(4):815-22

41. Toral C, et al: Effect of extracellular matrix on adhesion, viability, actin cytoskeleton and $\mathrm{K}+$ currents of cells expressing human ether a go-go channels. Life Sci 2007, 81(3):255-65.

42. Meyer $\mathrm{R}$, et al: Identification of ether a go-go and calcium-activated potassium channels in human melanoma cells. J Membr Biol 1999, 171(2):107-15.

43. Meyer R, Heinemann SH: Characterization of an eag-like potassium channel in human neuroblastoma cells. J Physiol 1998, 508(Pt 1):49-56.

44. Patt $S$, et al: Expression of ether a go-go potassium channels in human gliomas. Neurosci Lett 2004, 368(3):249-53.

45. Farias LM, et al: Ether a go-go potassium channels as human cervical cancer markers. Cancer Res 2004, 64(19):6996-7001.

46. Ousingsawat J, et al: Expression of voltage-gated potassium channels in human and mouse colonic carcinoma. Clin Cancer Res 2007, 13(3):824-31.

47. Ding XW, et al: Aberrant expression of Eag1 potassium channels in gastric cancer patients and cell lines. Med Oncol 2007, 24(3):345-50.

48. Mello de Queiroz F, et al: Ether a go-go potassium channel expression in soft tissue sarcoma patients. Mol Cancer 2006, 5:42.

49. Arcangeli $A$, et al: A novel inward-rectifying $K+$ current with a cell-cycle dependence governs the resting potential of mammalian neuroblastoma cells. J Physiol 1995, 489(Pt 2):455-71.

50. Hofmann $\mathrm{G}$, et al: HERG K+ channels activation during beta(1) integrinmediated adhesion to fibronectin induces an up-regulation of alpha(v) beta(3) integrin in the preosteoclastic leukemia cell line FLG 29.1. J Biol Chem 2001, 276(7):4923-31.

51. Smith GA, et al: Functional up-regulation of HERG K+ channels in neoplastic hematopoietic cells. J Biol Chem 2002, 277(21):18528-34

52. Crociani $\mathrm{O}$, et al: Cell cycle-dependent expression of HERG1 and HERG1B isoforms in tumor cells. J Biol Chem 2003, 278(5):2947-55.
53. Suzuki T, Takimoto K: Selective expression of HERG and Kv2 channels influences proliferation of uterine cancer cells. Int J Oncol 2004, 25(1):153-9.

54. Shao $X D$, et al: The potent inhibitory effects of cisapride, a specific blocker for human ether-a-go-go-related gene (HERG) channel, on gastric cancer cells. Cancer Biol Ther 2005, 4(3):295-301.

55. Masi $\mathrm{A}$, et al: hERG1 channels are overexpressed in glioblastoma multiforme and modulate VEGF secretion in glioblastoma cell lines. $\mathrm{Br}$ Cancer 2005, 93(7):781-92.

56. Cherubini $A$, et al: HERG potassium channels are more frequently expressed in human endometrial cancer as compared to non-cancerous endometrium. Br J Cancer 2000, 83(12):1722-9.

57. Pillozzi $\mathrm{S}$, et al: HERG potassium channels are constitutively expressed in primary human acute myeloid leukemias and regulate cell proliferation of normal and leukemic hemopoietic progenitors. Leukemia 2002, 16(9):1791-8.

58. Bauer $\mathrm{CK}$, et al: HERG $\mathrm{K}(+)$ currents in human prolactin-secreting adenoma cells. Pflugers Arch 2003, 445(5):589-600.

59. Lastraioli $E$, et al: herg1 gene and HERG1 protein are overexpressed in colorectal cancers and regulate cell invasion of tumor cells. Cancer Res 2004, 64(2):606-11

60. Shao XD, et al: Expression and significance of HERG protein in gastric cancer. Cancer Biol Ther 2008, 7(1):45-50.

61. Afrasiabi $E_{\text {, et }}$ al: Expression and significance of HERG $(\mathrm{KCNH} 2)$ potassium channels in the regulation of MDA-MB-435 S melanoma cell proliferation and migration. Cell Signal 22(1):57-64.

62. Wadhwa S, et al: Differential expression of potassium ion channels in human renal cell carcinoma. Int Urol Nephrol 2008.

63. Ding XW, et al: Aberrant expression of ether a go-go potassium channe in colorectal cancer patients and cell lines. World J Gastroenterol 2007 13(8):1257-61.

64. Agarwal JR, et al: The potassium channel Ether a go-go is a novel prognostic factor with functional relevance in acute myeloid leukemia. Mol Cancer 2010, 9:18.

65. Diaz $L$, et al: Estrogens and human papilloma virus oncogenes regulate human ether-a-go-go-1 potassium channel expression. Cancer Res 2009, 69(8):3300-7.

66. Borowiec AS, et al: IGF-1 activates hEAG $\mathrm{K}(+)$ channels through an Aktdependent signaling pathway in breast cancer cells: role in cell proliferation. J Cell Physiol 2007, 212(3):690-701.

67. Gavrilova-Ruch O, Schonherr R, Heinemann SH: Activation of hEAG1 potassium channels by arachidonic acid. Pflugers Arch 2007, 453(6):891-903.

68. Stuhmer W, et al: Potassium channels as tumour markers. FEBS Lett 2006 580(12):2850-2.

69. Bruggemann A, Stuhmer W, Pardo LA: Mitosis-promoting factor-mediated suppression of a cloned delayed rectifier potassium channel expressed in Xenopus oocytes. Proc Natl Acad Sci USA 1997, 94(2):537-42.

70. Pardo LA, et al: Cell cycle-related changes in the conducting properties of r-eag K+ channels. J Cell Biol 1998, 143(3):767-75.

71. Camacho J, et al: Cytoskeletal interactions determine the electrophysiological properties of human EAG potassium channels. Pflugers Arch 2000, 441(2-3):167-74.

72. Arcangeli A: Expression and role of hERG channels in cancer cells. Novartis Found Symp 2005, 266:225-32, discussion 232-4.

73. Xia Z, et al: The antidepressants imipramine, clomipramine, and citalopram induce apoptosis in human acute myeloid leukemia HL-60 cells via caspase-3 activation. J Biochem Mol Toxicol 1999, 13(6):338-47.

74. Wang $\mathrm{H}$, et al: HERG $\mathrm{K}+$ channel, a regulator of tumor cell apoptosis and proliferation. Cancer Res 2002, 62(17):4843-8.

75. Nilius B, Schwarz G, Droogmans $\mathrm{G}$ : Control of intracellular calcium by membrane potential in human melanoma cells. Am J Physiol 1993, 265(6 Pt 1):C1501-10.

76. Whitaker M, Patel R: Calcium and cell cycle control. Development 1990, 108(4):525-42

77. Rouzaire-Dubois B, Dubois JM: A quantitative analysis of the role of $\mathrm{K}+$ channels in mitogenesis of neuroblastoma cells. Cell Signal 1991, 3(4):333-9.

78. Rouzaire-Dubois B, Dubois JM: K+ channel block-induced mammalian neuroblastoma cell swelling: a possible mechanism to influence proliferation. J Physiol 1998, 510(Pt 1):93-102. 
79. Abbott NJ: Astrocyte-endothelial interactions and blood-brain barrier permeability. J Anat 2002, 200(6):629-38.

80. Bender $A S$, et al: Ionic mechanisms in glutamate-induced astrocyte swelling: role of K+ influx. J Neurosci Res 1998, 52(3):307-21.

81. Bertout JA, Patel SA, Simon MC: The impact of $\mathrm{O} 2$ availability on human cancer. Nat Rev Cancer 2008, 8(12):967-75.

82. Hegle AP, Marble DD, Wilson GF: A voltage-driven switch for ionindependent signaling by ether-a-go-go K+ channels. Proc Natl Acad SCl USA 2006, 103(8):2886-91.

83. Sun $X X$, et al: The eag potassium channel binds and locally activates calcium/calmodulin-dependent protein kinase II. J Biol Chem 2004, 279(11):10206-14.

84. Colomer J, Means AR: Physiological roles of the $\mathrm{Ca} 2+/ \mathrm{CaM}$-dependent protein kinase cascade in health and disease. Subcell Biochem 2007, 45:169-214.

85. Hemmerlein B, et al: Overexpression of Eag1 potassium channels in clinical tumours. Mol Cancer 2006, 5:41.

86. Pardo LA, Stuhmer W: Eag1: an emerging oncological target. Cancer Res 2008, 68(6):1611-3.

87. Garcia-Ferreiro RE, et al: Mechanism of block of hEag1 K+ channels by imipramine and astemizole. J Gen Physiol 2004, 124(4):301-17.

88. Gavrilova-Ruch O, et al: Effects of imipramine on ion channels and proliferation of IGR1 melanoma cells. J Membr Biol 2002, 188(2):137-49.

89. Gomez-Varela D, et al: Monoclonal antibody blockade of the human Eag1 potassium channel function exerts antitumor activity. Cancer Res 2007, 67(15):7343-9.

90. Weber $C$, et al: Silencing the activity and proliferative properties of the human Eagl Potassium Channel by RNA Interference. J Biol Chem 2006, 281(19):13030-7.

91. Zhao J, et al: Silencing of herg gene by shRNA inhibits SH-SY5Y cell growth in vitro and in vivo. Eur J Pharmacol 2008, 579(1-3):50-7.

92. Furlan F, et al: ERG conductance expression modulates the excitability of ventral horn GABAergic interneurons that control rhythmic oscillations in the developing mouse spinal cord. J Neurosci 2007, 27(4):919-28.

93. Overholt $\mathrm{J}$, et al: HERG-Like potassium current regulates the resting membrane potential in glomus cells of the rabbit carotid body. J Neurophysiol 2000, 83(3):1150-7.

94. Farrelly AM, et al: Expression and function of KCNH2 (HERG) in the human jejunum. Am J Physiol Gastrointest Liver Physiol 2003, 284(6): G883-95.

95. Gullo F, et al: ERG K+ channel blockade enhances firing and epinephrine secretion in rat chromaffin cells: the missing link to LQT2-related sudden death? FASEB J 2003, 17(2):330-2.

96. Rosati B, et al: Glucose- and arginine-induced insulin secretion by human pancreatic beta-cells: the role of HERG $\mathrm{K}(+)$ channels in firing and release. FASEB J 2000, 14(15):2601-10.

doi:10.1186/1477-7819-8-113

Cite this article as: Asher et al: Eag and HERG potassium channels as novel therapeutic targets in cancer. World Journal of Surgical Oncology 2010 8:113.

\section{Submit your next manuscript to BioMed Central and take full advantage of:}

- Convenient online submission

- Thorough peer review

- No space constraints or color figure charges

- Immediate publication on acceptance

- Inclusion in PubMed, CAS, Scopus and Google Scholar

- Research which is freely available for redistribution 